\title{
Nutrition and Chemotaxis in the Myxomycete Physarum polycephalum: the Effect of Carbohydrates on the Plasmodium
}

\author{
By M. J. CARLILE \\ Department of Biochemistry, Imperial College of Science and Technology, \\ London S.W.7
}

(Accepted for publication Io July 1970)

SUMMARY

The ability of a range of carbohydrates to support the growth of plasmodia of the myxomycete Physarum polycephalum was investigated and a method for the objective study of the chemotaxis of plasmodia was developed. Plasmodia showed positive chemotaxis to solutions of glucose, maltose, mannose and peptone, and to galactose after a delay. They did not respond to sucrose, fructose or ribose. The chemotactic effectiveness of sugars paralleled their ability to support growth.

\section{INTRODUCTION}

There are a number of early reports of the attraction (positive chemotaxis) of myxomycete plasmodia to nutrient solutions and to extracts of micro-organisms. Many of these reports-cited and briefly reviewed by Hawker (1952) and Ziegler (I962)are of limited value. Assessment of chemotaxis was commonly subjective and, since pure cultures were not available, the agents studied could have acted indirectly through their effects on microbial contaminants. The lack of pure cultures and soluble media also prevented quantitative nutritional studies, which alone could determine whether the attractants were themselves nutrients or acted in some other manner. One of the more convincing of the early studies was that of Coman (1940), who found that plasmodia of Physarum polycephalum Schweinitz responded to glucose solutions by positive chemotaxis but were indifferent to sucrose solutions. Since this study, the pure culture of plasmodia of $P$. polycephalum on liquid media has been achieved (Daniel \& Rusch, 196I). It therefore seemed desirable to confirm Coman's finding with pure cultures, to investigate the effects of other carbohydrates and to ascertain whether there was a correlation between the chemotactic effectiveness of carbohydrates and their ability to support growth.

\section{METHODS}

Organism and routine culture. Physarum polycephalum strain $a+i$ (Dee, I962) was maintained in pure culture on liquid and agar media. The standard medium was a modification of the semidefined medium advocated by Daniel \& Baldwin (I964) and contained the following constituents $(\%, \mathrm{w} / \mathrm{v})$ : glucose, $\mathrm{I} \cdot \mathrm{O}$; bacteriological peptone (Oxoid), I.0; citric acid. $\mathrm{H}_{2} \mathrm{O}, 0.354 ; \mathrm{CaCl}_{2} .6 \mathrm{H}_{2} \mathrm{O}, 0.06 ; \mathrm{Na}_{2}$ EDTA, 0.022; $\mathrm{FeCl}_{2} .4 \mathrm{H}_{2} \mathrm{O}, 0.006 ; \mathrm{ZnSO}_{4} .7 \mathrm{H}_{2} \mathrm{O}, 0.003$; thiamin hydrochloride, 0.004; biotin, 0.0005 ; haem, 0.0005 ; distilled water: $\mathrm{pH}$ adjusted to 4.6 . Details of the preparation and sterilization of this medium and of culture methods are given elsewhere (Carlile, 
1970). All experiments were carried out at $24^{\circ}$ and aseptic procedures were employed throughout.

Nutritional studies. Cultures $(50 \mathrm{ml}$. medium in $500 \mathrm{ml}$. Erlenmeyer flasks) were shaken at $200 \mathrm{rev} . / \mathrm{min}$. on a rotary shaker with radius of gyration $4.5 \mathrm{~cm}$. Plasmodia were centrifuged, the culture medium decanted, the plasmodia resuspended in distilled water, centrifuged again, dried overnight at $110^{\circ}$ and weighed.

Assessment of chemotaxis. Tests on the chemotactic effectiveness of sugars were carried out on Petri plates of sugar-free standard agar medium from which two wells and a central trough had been excised (Pl. I). Distilled water was placed in one well and an equal volume of sugar solution in the other and the dish left for $I$ to 4 days for the sugar to diffuse through the agar to the edge of the trough. A massive plasmodial inoculum was allowed to spread for I to 4 days on sugar-free standard medium to deplete carbohydrate reserves, and a square of plasmodium with underlying agar was excised and deposited in the centre of the trough. Migration of the plasmodium was observed daily, or more frequently if necessary; slime tracks indicated the path taken by the plasmodium. Chemotaxis to peptone was studied on peptone-free standard medium with plasmodia that had migrated on that medium, and chemotaxis to the complete medium on plain agar $\left(\mathrm{pH}_{4} \cdot 6\right)$ with plasmodia from plain agar.

An individual test was recorded as being positive if the plasmodium had reached the well containing the test solution but had not reached the control well, and negative if the control well was reached first. On occasions when a plasmodium came into contact with both wells or with neither well, the individual test was regarded as unsuccessful and was not included in the total count. In a set of ten tests, the most probable outcome of random migration is five positive results whereas positive or negative chemotaxis may yield ten or zero positive results respectively. The significance of an experiment or group of experiments was assessed by means of the binomial distribution (Snedecor \& Cochran, 1967).

\section{RESULTS}

\section{Nutritional studies}

A typical experiment on the growth of plasmodia on standard medium is illustrated in Fig. I. Virtually no lag phase occurred, and growth rate (doubling time about $12 \mathrm{~h}$.) and yield were comparable to, or greater than, the highest reported by other workers (Daniel \& Rusch, I96I; Daniel \& Baldwin, I964; Brewer, Kuraishi, Garver \& Strong, 1964). When glucose was omitted from the standard medium, little growth occurred (Table I; Fig. I), although plasmodia remained active (showed streaming) for at least 2 weeks. On agar media lacking glucose, plasmodia eroded and ultimately burrowed into the agar, behaviour not seen on cultures with adequate glucose. The omission of peptone from standard medium resulted in little or no growth and rapid sclerotium formation, whether or not glucose was present. The omission of citric acid (S. Barnes, personal communication) did not affect growth rate and final yields, but affected morphology, plasmodia becoming very long and tangled. Citric acid was not utilized by plasmodia; its role in the standard medium appears to be that of a $\mathrm{pH}$ buffer and metal chelator.

The effect of replacing glucose by other carbohydrates is indicated in Table I. Maltose, glycogen, soluble starch and cellobiose were closely similar to glucose in 


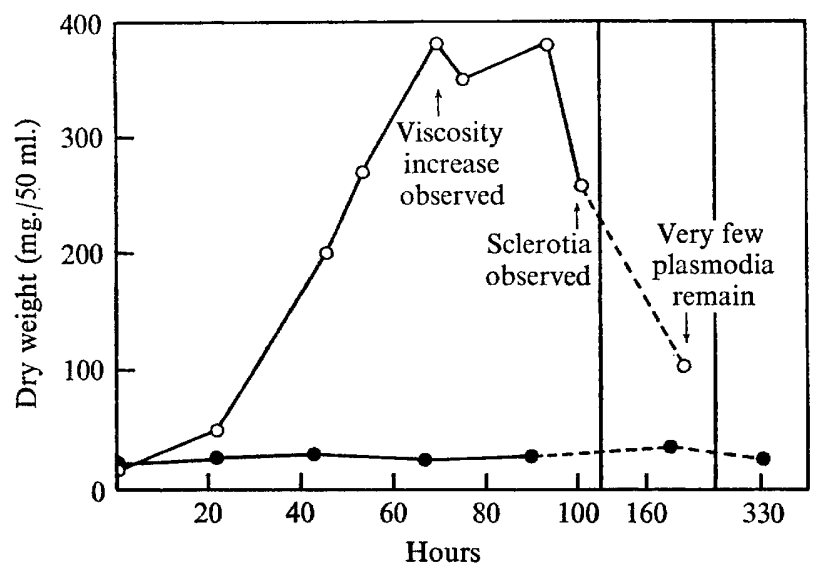

Fig. 1. Growth of plasmodia of Physarum polycephalum in shaken liquid culture. The inoculumi $(5 \%, 2.5 \mathrm{ml}$.) was from a vigorously growing culture. Standard medium, -O-O-; sugar-free standard medium,

Table I. Growth of plasmodia on standard media in which glucose was replaced by other carbohydrates

\begin{tabular}{|c|c|c|}
\hline Carbon source* & $\begin{array}{c}\text { Time of harvest } \\
\text { (days) } \dagger\end{array}$ & $\begin{array}{l}\text { Yield ( } \% \text { of dry wt } \\
\text { obtained with } \\
\text { glucose) } \ddagger\end{array}$ \\
\hline Glucose & 4 & 100 \\
\hline Maltose & 4 & 98 \\
\hline Cellobiose & 4 & 117 \\
\hline Glycogen (oyster) & 4 & 98 \\
\hline Soluble starch & 4 & 107 \\
\hline Glucan§ & 5 & 94 \\
\hline Mannose & 5 to 6 & 103 \\
\hline Trehalose & 6 & 89 \\
\hline Galactose & Io to II & 69 \\
\hline Lactose & IO & 65 \\
\hline Edifas B\| & 10 & 19 \\
\hline Arabinose & 10 & 2 \\
\hline Ribose & I I & 2 \\
\hline Xylose & Io & 2 \\
\hline Sorbose & Io & 3 \\
\hline Rhamnose & I I & I \\
\hline Fructose & 12 to 13 & 3 \\
\hline Sucrose & I 2 & 2 \\
\hline Dextran & IO & 4 \\
\hline Glucosamine $\mathrm{HCl}$ & 9 & I \\
\hline None & 9 to 12 & 2 \\
\hline
\end{tabular}

* Carbohydrate solutions were autoclaved separately from the other components of the medium and aseptically added to them when cool to give a medium containing $\mathrm{I} \%(\mathrm{w} / \mathrm{v})$ carbohydrate.

$\dagger$ Harvesting was carried out at the time of maximal growth (estimated visually).

$\ddagger$ Average of at least three cultures. Controls $(a)$ with glucose and $(b)$ lacking any carbohydrate were included in all experiments. To minimize the carry-over of glucose the inoculum was taken from cultures that had already attained maximum growth on standard medium. A yield of $1 \%$ represents no growth, as $1 \%$ inocula were employed.

$\S \mathrm{A} \beta_{\mathrm{I}} \rightarrow 3$ linked glucan with $\beta \mathrm{I} \rightarrow 6$ branches, from Claviceps fusiformis (Buck, Chen, Dickerson \& Chain, I968).

\| Sodium carboxymethylcellulose (Imperial Chemical Industries, Ltd). The average degree of substitution is 0.7 to 0.8 ( 14 to $16 \%$ ), a value giving good solubility but permitting partial utilization by organisms able to utilize cellulose. 
their value as carbon sources, giving similar yields after the same number of days. Mannose, trehalose and a glucan gave comparable yields but rather more slowly. Galactose or lactose gave good growth after a lag phase of some days, but the increase in viscosity observed with other media giving good growth did not take place. Yields remained roughly constant for many days with sclerotia and plasmodia co-existing; the clearcut sequence of phases seen on media containing glucose did not occur. Lower but still appreciable yields were obtained with a soluble cellulose derivative. Little or no growth took place with arabinose, ribose, xylose, fructose, rhamnose, sorbose, sucrose, dextran or glucosamine hydrochloride.

\section{Studies on chemotaxis}

The chemotactic effectiveness of glucose was repeatedly demonstrated (Table 2) with both filter-sterilized and autoclaved glucose solutions. In all instances the plasmodia reached the experimental well without having come into contact with the control well. Strong positive chemotaxis was normally evident within I day of inoculation and the experiment could be terminated in 2 days. Maltose, mannose, peptone and standard medium (which contains glucose and peptone) gave similar results. Chemotaxis to both filter-sterilized and autoclaved galactose solutions occurred, but with a delay not experienced with maltose and mannose solutions. Observations at $\mathrm{I}$ day indicated apparently random initial migration and experiments were not terminable until the third or fourth day, by which time positive chemotaxis had taken place.

Table 2. Summary of experiments on chemotaxis

\begin{tabular}{|c|c|c|c|c|}
\hline Substance* & $\begin{array}{c}\text { Tests } \\
\text { successfully } \\
\text { completed }\end{array}$ & $\begin{array}{l}\text { Positive } \\
\text { responses } \\
\text { obtained }\end{array}$ & $\begin{array}{c}\text { Probability } \\
\text { of result } \\
(\%) \dagger\end{array}$ & Conclusion $\ddagger$ \\
\hline Glucose & 30 & 30 & $5 \times 10^{-6}$ & + \\
\hline Maltose & 10 & 10 & 0.2 & + \\
\hline Mannose & 9 & 9 & 0.4 & + \\
\hline Galactose & 8 & 8 & 0.8 & + \\
\hline Sucrose & I 8 & IO & $5 \mathrm{I}$ & 0 \\
\hline Fructose & 10 & 5 & 100 & 0 \\
\hline Ribose & Io & 4 & 75 & 0 \\
\hline Peptone & 30 & 30 & $5 \times 10^{-6}$ & + \\
\hline Standard medium & IO & 10 & 0.2 & + \\
\hline
\end{tabular}

* Sugar solutions $(1 \%, w / v)$ were filter-sterilized. Oxoid bacteriological peptone $(1 \%$, $w / v)$ and standard medium were autoclaved.

$\dagger$ Probability ( $\%$ ) of the experimental finding being due to random migration.

$\ddagger+=$ Positive chemotaxis; $0=$ random migration.

Chemotaxis to sucrose, fructose and ribose solutions did not occur, although strong positive chemotaxis was observed in control experiments carried out simultaneously with glucose.

\section{DISCUSSION}

Nutritional requirements. The omission of glucose from standard medium results in growth yields of as low as $2 \%$ of those given by control cultures (Table I); this establishes that peptone cannot act as sole carbon source for the growth of Physarum polycephalum. The high yields obtained in the absence of added carbohydrates by earlier workers, $29 \%$ (Daniel \& Rusch, I96I) and 36 to $49 \%$ (Daniel \& Baldwin, I964) 
of control cultures, are probably due to the presence of large amounts of yeast extract in their media, as are the high yields ( $52 \%$ of control cultures) obtained with $P$. rigidum (Henney \& Henney, 1968).

The report (Daniel \& Baldwin, 1964) that glucose can be replaced by maltose or soluble starch, but not by sorbose, xylose or arabinose, has been confirmed. Their claim that fructose can be utilized was not confirmed (and is not supported by their own table showing a yield with fructose which differed little from that of their sugarfree controls); nor was their statement that galactose is not utilized supported by our findings. Results on another myxomycete, Physarum rigidum, are in complete agreement with those reported here; Henney \& Henney (I968) found that glucose, mannose, lactose and galactose were utilized and that fructose, sucrose, arabinose, ribose and xylose were not.

Chemotaxis. Coman (1940) found that plasmodia of Physarum polycephalum respond to glucose solutions by positive chemotaxis but are indifferent to sucrose. The present study confirms Coman's findings, and demonstrates that with the seven sugars studied there is a complete correlation between their ability to support growth and their chemotactic effectiveness. Positive chemotaxis to peptone also occurs, thus taxis to nutrients is not limited to sugars. Taxis to standard medium is presumably attributable to glucose, peptone and possibly other nutrients.

If a nutrient is lacking, or is available only in a growth-limiting concentration, it will be advantageous for the plasmodium to respond by positive chemotaxis to fresh supplies of that nutrient. If other nutrients are also lacking, or are only present in low concentrations then the requirement for the test nutrient will soon be satisfied and chemotaxis will not continue. Hence the agar-solidified medium which was employed both for the preparation of the plasmodial inoculum and the actual assay, contained in abundance all the nutrients required by the organism except the one being tested. Preliminary experiments indicated that it was this feature of the assay that led to the achievement of highly consistent results. The principle is one generally applicable to the design of assays for the study of nutritional chemotropism and chemotaxis (Harris 196I ; Rosen, 1962, Adler, I966; Carlile, 1966) and is likely to be crucial wherever the response takes hours or days rather than minutes.

I wish to thank Dr J. Dee for providing strain $a+i$, Mr S. Barnes, Dr K. W. Buck and Dr A. G. F. Dickerson for advice on carbohydrate biochemistry and metabolism, Dr A. L. Cooper for access to calculations on glucose diffusion, Miss S. Ford for photography, Mr C. E. Groome for skilled technical assistance, and Professor Sir Ernst Chain, F.R.S. for helpful discussion.

\section{REFERENCES}

Adler, J. (1966). Chemotaxis in bacteria. Science, New York 153, 708-716.

Brewer, E. N., Kuraishi, S., Garver, J. C. \& Strong, F. M. (1964). Mass culture of a slime mould, Physarum polycephalum. Applied Microbiology 12, 16I-I64.

Buck, K. W., Chen, A. W., Dickerson, A. G. \& Chain, E. B. (i968). Formation and structure of extracellular glucans produced by Claviceps species. Journal of General Microbiology 51, 337-352.

Carlile, M. J. (1966). The orientation of zoospores and germ-tubes. In The Fungus Spore, pp. I75-I 87. Edited by M. F. Madelin. London: Butterworths.

Carlile, M. J. (1970). Myxomycetes and other slime moulds. In Methods in Microbiology, vol. 4. Edited by C. Booth. London: Academic Press. 
Coman, D. R. (1940). Additional observations on positive and negative chemotaxis. Experiments with a myxomycete. Archives of Pathology 29, 220-228.

DANIEL, J. W. \& BALDWIN, H. H. (1964). Methods of culture for plasmodial myxomycetes. In Methods in Cell Physiology, vol. I, pp. 9-4I. Edited by D. M. Prescott. New York: Academic Press.

Daniel, J. W. \& Rusch, H. P. (1961). The pure culture of Physarum polycephalum on a partially defined soluble medium. Journal of General Microbiology 25, 47-59.

DEE, J. (1962). Recombination in a myxomycete, Physarum polycephalum Schw. Genetical Research 3, II -23 .

HARrIS, H. (196I). Chemotaxis. Experimental Cell Research 8, Supplement, 199-208.

HAWKeR, L. E. (1952). The physiology of myxomycetes. Transactions of the British Mycological Society 35, 177-187.

HENNEY, H. R. \& HENNEY, M. R. (1968). Nutritional requirements for the growth in pure culture of the myxomycete Physarum rigidum and related species. Journal of General Microbiology 53, 333-339.

Rosen, W. G. (1962). Cellular chemotropism and chemotaxis. Quarterly Review of Biology 37, 242-259.

SNedeCOR, G. W. \& Cochran, W. G. (1967). Statistical methods, 6th edn. Ames, Iowa: Iowa State University Press.

Ziegler, H. (1962). Chemotaxis. In Encyclopaedia of Plant Physiology, vol. 17, part 2, pp. 484-532. Edited by W. Ruhland. Berlin: Springer.

\section{EXPLANATION OF PLATE}

Positive chemotaxis of plasmodium of Physarum polycephalum. Glucose solution on left, distilled water on right. $\times \mathbf{I} \cdot 5$. 
Journal of General Microbiology, Vol. 63, No. 2

Plate I

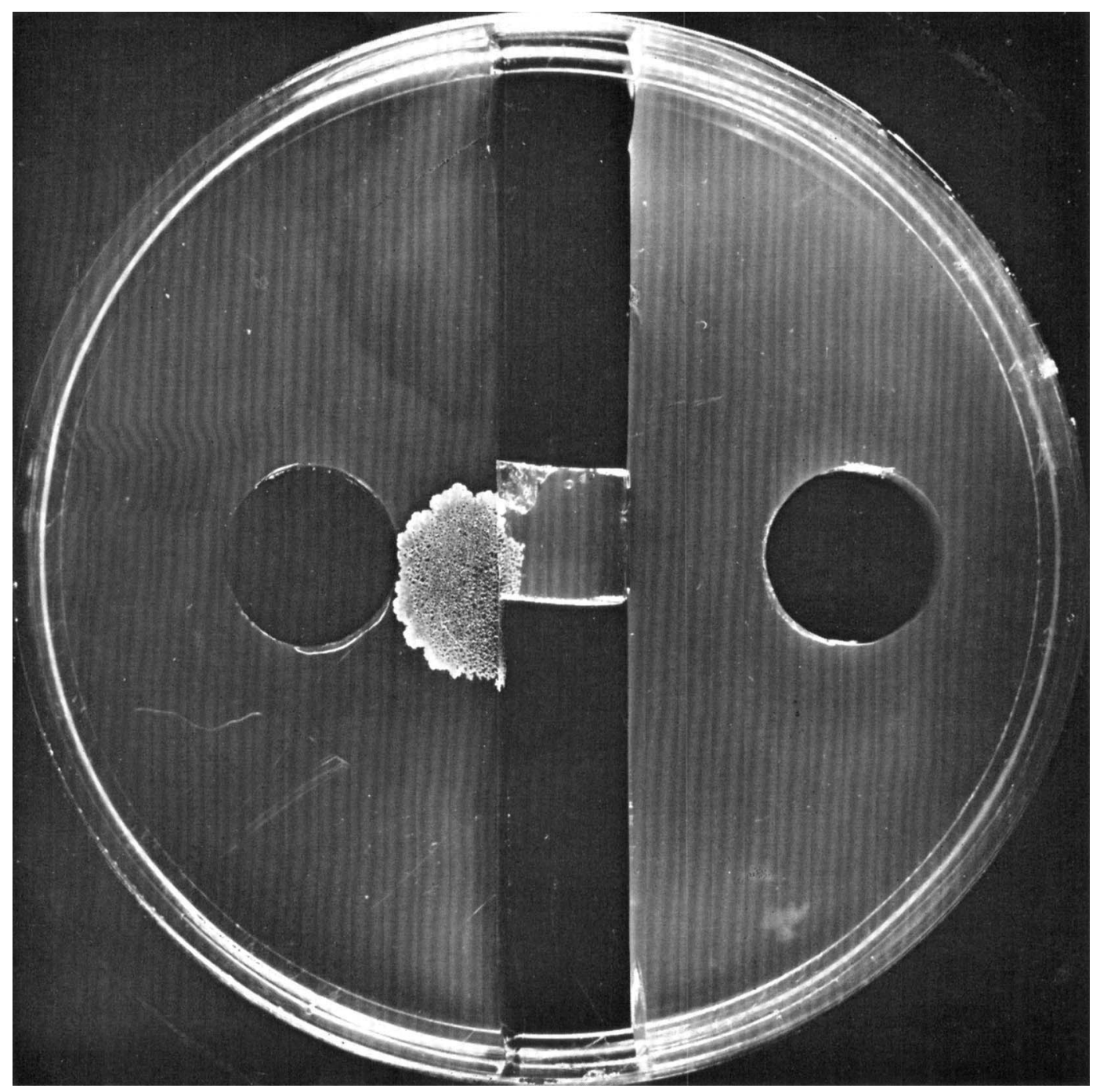

